\title{
Mechanistic and kinetic insight into spontaneous cocrystallisation of isoniazid and benzoic acid
}

Inese Sarceviča*a,b, Liāna Orola ${ }^{\mathrm{a}}$, Karol P. Nartowski ${ }^{\mathrm{b}}$, Yaroslav Z. Khimyak ${ }^{\mathrm{b}}$, Andrew N. Round ${ }^{\mathrm{b}}$ and László Fábián*b

${ }^{a}$ University of Latvia, Department of Chemistry, K.Valdemara street 48, Riga, Latvia, LV1013.

${ }^{b}$ University of East Anglia, School of Pharmacy, Norwich Research Park, Norwich, Norfolk, NR4 7TJ, UK.

* To whom correspondence should be addressed: Inese Sarceviča, E-mail: inese.sarcevica@lu.lv; László Fábián, E-mail: 1.fabian@uea.ac.uk. 


\begin{abstract}
Solid-state cocrystallisation is of contemporary interest, because it offers an easy and efficient way to produce cocrystals, which are recognized as prospective pharmaceutical materials. Research explaining solid-state cocrystallisation mechanisms is important, but still too scarce to give a broad understanding of factors governing and limiting these reactions. Here we report an investigation of the mechanism and kinetics of isoniazid cocrystallisation with benzoic acid. This reaction is spontaneous; however its rate is greatly influenced by environmental conditions (humidity and temperature) and pre-treatment (milling) of the sample. The acceleration of cocrystallisation in the presence of moisture is demonstrated by kinetic studies at elevated humidity. The rate dependence on humidity stems from moisture facilitated rearrangements on the surface of isoniazid crystallites, which lead to cocrystallisation in the presence of benzoic acid vapour. Furthermore, pre-milling the mixture of the cocrystal ingredients eliminated the induction time of the reaction and considerably increased its rate.
\end{abstract}

Keywords: Cocrystallisation; mechanochemistry; effect of spinning; spontaneous reactions; solidstate kinetics.

\title{
Introduction
}

In recent years, pharmaceutical cocrystals have attracted the attention of scientists as prospective materials with tuneable properties. For example, cocrystals of active pharmaceutical ingredients (API) offer better stability, ${ }^{1,2}$ solubility ${ }^{3}$ and bioavailability ${ }^{4}$ compared to their parent drugs. However, before cocrystals are produced industrially, a sufficient understanding of the conditions governing their formation and decomposition into separate compounds must be acquired to evaluate their stability. Cocrystals can form spontaneously in physical mixtures of their compounds, $^{5-8}$ but purposefully they are prepared by crystallisation from solvent, ${ }^{9-15}$ from 
melt, ${ }^{16,17}$ by spray drying ${ }^{18,19}$ or by mechanical treatment. ${ }^{20-22}$ The latter method has gained recognition in scientific laboratories and is employed extensively to synthesize new polymorphs, cocrystals and salts. It is fast, easy to perform, requires minimal or no use of solvent ${ }^{23}$ and offers a pure product with a controlled polymorphic yield. ${ }^{22}$ In addition, mechanochemistry allows interconversion between salts ${ }^{24}$ and cocrystals ${ }^{25}$ of different stoichiometry. However, a current drawback of this method is the large number of unknown parameters that can influence the outcome of the reaction. Such parameters are relative humidity, ${ }^{26}$ temperature rise and force distribution ${ }^{27}$ in the reaction vessel during milling. The mechanical force can act on the compounds by friction, shear and impact and each of these effects can lead to a different product. ${ }^{27}$ The mechanical treatment can introduce various changes in the crystalline material including crystal defects, strain and partial amorphisation, as well as a reduced size of crystallites, ${ }^{28,29}$ thereby increasing the reactivity of crystalline compounds. Mechanochemical reactions can proceed through different routes involving amorphisation ${ }^{30}$ or liquid phase (eutectic melt) formation. ${ }^{31}$ Experimental observations indicate that some systems undergo transitions only during milling ${ }^{32}$ and the reaction terminates on stopping the treatment, while other systems can continue to react after removing the mechanical impact. ${ }^{30,33}$

Another parameter influencing the outcome of mechanosynthesis is relative humidity. High humidity can lead to moisture sorption which plays an important role in cocrystallisation reactions. ${ }^{5,7,34}$ The water uptake is enhanced when using hygroscopic cocrystal components ${ }^{8}$ or by the presence of deliquescent additives ${ }^{8}$ and amorphous phase. ${ }^{34}$ In most of the moisture facilitated reactions water has been shown to partially dissolve the compounds and to allow nucleation of cocrystal in the liquid phase. ${ }^{8,31,35}$

Although valuable work towards understanding mechanochemical and spontaneous supramolecular reactions of organic compounds has already been performed, ${ }^{25,27,36-40}$ there are still several uncertainties left. Useful information about the mechanisms of cocrystallisation and environmental conditions governing cocrystal formation and decomposition into its compounds can be extracted from kinetic data. However, the interpretation of kinetics in terms of solid-state 
reaction mechanisms is not straightforward and often requires sets of additional measurements to confirm and to explain the proposed reaction mechanisms. This report aims to consider and to evaluate the experimental conditions influencing the rate of mechanochemical cocrystal formation. The antitubercular drug isoniazid was chosen as a model compound, since it is known to form cocrystals with acids ${ }^{41-52}$; and its cocrystals can be obtained mechanochemically. ${ }^{47,53}$ Furthermore, the isoniazid-benzoic acid cocrystal forms spontaneously and cocrystallisation is accelerated by pre-milling the reactant mixture. The rate of this reaction depends on the environmental conditions of storage and on pre-treatment of the sample. To discover the effect of these parameters on the rate of cocrystal formation, a series of experiments were carried out. Parameters such as relative humidity, temperature and the initial milling frequency were considered in the course of these experiments. In addition, we demonstrate the impact of the sample spinning speed under conditions of magic angle spinning (MAS) solid-state NMR analysis as one of the factors that substantially increases the rate of cocrystallisation.

\section{Experimental Section}

Materials. Benzoic acid and isoniazid were procured from commercial suppliers. $5 \mathrm{~g}$ of isoniazid and $5 \mathrm{~g}$ of benzoic acid were milled separately in the Retsch MM301 ball mill (10 mL stainless steel vials with one $1 \mathrm{~cm}$ stainless steel ball in each) for 15 minutes to reduce the particle size. The milled samples were annealed by keeping at ambient conditions for 2 weeks and sieved to obtain the fraction of 75 to $150 \mu \mathrm{m}$.

Mechanochemical cocrystallisation. $0.2743 \mathrm{~g}$ of isoniazid and $0.2442 \mathrm{~g}$ of benzoic acid $(1: 1$ molar ratio) were gently blended together in a mortar with the pestle before co-milling to reduce the effect of composition inhomogeneity. Cocrystallisation was performed by milling the mixture of the starting compounds in a Retsch MM301 ball mill. Isoniazid and benzoic acid were milled in $5 \mathrm{~mL}$ stainless steel grinding jars with one $6 \mathrm{~mm}$ stainless steel ball in each milling jar. For kinetic experiments milling was performed with two $8 \mathrm{~mm}$ and three $6 \mathrm{~mm}$ stainless steel balls in each milling jar. Two different milling ball sizes were chosen after initial experiments, since they offered better data reproducibility compared to equally sized milling balls. Samples were ground at ambient conditions (45-55\% relative humidity (RH) and $20-22{ }^{\circ} \mathrm{C}$ ) for various time periods with a frequency of 20,25 or $30 \mathrm{~Hz}$. The average composition of the reaction mixture after milling was determined 
by removing the powder from the grinding jar and quickly mixing it in a mortar to homogenize the composition. The milling product was analysed by powder X-ray diffraction (PXRD) immediately after the experiment.

Cocrystallisation kinetics in pre-milled isoniazid and benzoic acid 1:1 mixtures. The cocrystallisation kinetics in pre-milled isoniazid and benzoic acid 1:1 mixture $(0.2743 \mathrm{~g}$ of isoniazid and $0.2442 \mathrm{~g}$ of benzoic acid) was investigated using in situ powder X-ray diffraction experiments at elevated temperature and relative humidity. The pre-milled mixtures were loaded into the humidity chamber and subsequent diffraction patterns were recorded until no further changes in the diffraction patterns were observed. Several sets of experiments were performed to evaluate the effect of relative humidity, temperature and the initial milling frequency. The effect of the temperature was studied by performing experiments at $35,40,45,50$ and $55^{\circ} \mathrm{C}$ temperature and $60 \% \mathrm{RH}$ for samples that were pre-milled for 5 minutes at $20 \mathrm{~Hz}$. The influence of the relative humidity was evaluated by acquiring the X-ray diffraction data at 60,70 and $80 \% \mathrm{RH}$ and $40{ }^{\circ} \mathrm{C}$ for samples that were pre-milled for 5 minutes at 20 and $25 \mathrm{~Hz}$. The influence of the pre-milling frequency was considered by performing the milling for 5 minutes with a frequency of 20, 25, 30 $\mathrm{Hz}$ and recording the kinetic data of cocrystallisation at $60 \% \mathrm{RH}$ and $40{ }^{\circ} \mathrm{C}$.

In-situ PXRD at controlled temperature and humidity. The cocrystallisation experiments of isoniazid and benzoic acid were performed using a Bruker AXS D8 Discover powder diffractometer (Bruker AXS GmbH, Germany) equipped with an MRI humidity chamber. Copper $\mathrm{K}_{\alpha}$ radiation $(\lambda=1.5418 \AA$ ) was used in the experiments. Data were collected using a flat sample (depth of $0.8 \mathrm{~mm}$ ) holder in the Bragg-Brentano geometry.

The X-ray diffraction measurements were performed at various temperatures $(35,40,45,50$ and $\left.55^{\circ} \mathrm{C}\right)$ and various $\mathrm{RH}(60,70,80 \%)$. Diffraction patterns were recorded with $0.02^{\circ}$ step size and a scan speed of $0.1 \mathrm{~s}$ per step in the $2 \theta$ range from 3 to $30^{\circ}$.

Spontaneous cocrystallisation kinetics in isoniazid and benzoic acid 1:1 physical mixtures. Physical mixtures (1:1) of isoniazid (0.0686 g) and benzoic acid (0.0611 g) were stored in desiccators with various relative humidity $(38,58,75,84$ and $97 \% \mathrm{RH})$ at $30{ }^{\circ} \mathrm{C}$. Diffraction patterns were periodically recorded over a period of 27 days. The humidity in the desiccators was maintained using saturated salt solutions ( $\mathrm{NaI}$ for $38 \% \mathrm{RH}$; $\mathrm{NaBr}$ for $58 \% \mathrm{RH}$; $\mathrm{NaCl}$ for $75 \% \mathrm{RH}$; $\mathrm{KCl}$ for $84 \% \mathrm{RH}$ and $\mathrm{K}_{2} \mathrm{SO}_{4}$ for $\left.97 \% \mathrm{RH}\right) .{ }^{54}$

\section{Cocrystallisation in pre-milled 1:1 mixtures of isoniazid and benzoic acid at elevated} temperature and dry air. Pre-milled $(20 \mathrm{~Hz}, 5 \mathrm{~min})$ isoniazid and benzoic acid 1:1 mixtures were stored in desiccators containing $\mathrm{P}_{2} \mathrm{O}_{5}$ to ensure dry air. These desiccators were maintained at 30, 50 and $70{ }^{\circ} \mathrm{C}$ temperature. The composition of the samples was monitored using PXRD analysis.

Powder X-ray Diffraction (PXRD). Powder X-ray diffraction analysis of the isoniazid and 
benzoic acid physical mixtures kept at various relative humidity and pre-milled mixtures kept at dry air was performed using a Bruker AXS D8 Advance powder diffractometer (Bruker AXS GmbH, Germany) equipped with a LynxEye position sensitive detector and $\mathrm{Cu} K \alpha$ radiation $(\lambda=1.5418 \AA$ ), $40 \mathrm{kV}, 40 \mathrm{~mA}$. Diffraction patterns were recorded with a $0.02^{\circ}$ step size and a scan speed of $0.1 \mathrm{~s}$ per step in the $2 \theta$ range from 3 to $35^{\circ}$.

Rietveld analysis. The quantitative Rietveld analysis of the X-ray diffraction data were performed using the Bruker Topas 4.2 software $^{55}$ with the fundamental parameters (FP) approach. The crystal structures of isoniazid ${ }^{56}$ (CSD refcode INICAC01), benzoic acid ${ }^{57}$ (CSD refcode BENZAC01) and the isoniazid - benzoic acid cocrystal ${ }^{53}$ (CSD refcode SETRIU, 10.5517/ccyw9jm) were obtained from the Cambridge Structural Database (CSD) ${ }^{58}$ and used in the calculations.

A $3^{\text {rd }}$ order Chebyschev polynomial was used to describe the background of the powder patterns. It was assumed that the sample is crystalline and does not contain an amorphous phase, as significant background changes were not observed during the experiments. The unit cell parameters were refined and the results were corrected for absorption and sample displacement. The average composition of the sample over the time period necessary to record the pattern was obtained and ascribed to the midpoint of the pattern recording time.

Cocrystallisation in 1:1 unmilled and pre-milled mixtures of isoniazid and benzoic acid under conditions of Magic Angle Spinning (MAS) using solid-state NMR. Physical mixtures $(1: 1)$ and pre-milled mixtures $(5 \mathrm{~min}, 20 \mathrm{~Hz})$ of isoniazid $(0.2743 \mathrm{~g})$ and benzoic acid $(0.2442 \mathrm{~g})$ were prepared according to the procedure described in the previous sections immediately before solid-state NMR analysis. The materials were packed in zirconia rotors and placed in the NMR probe immediately after the sample preparation to avoid any impact of environmental changes. ${ }^{1} \mathrm{H}-$ ${ }^{13} \mathrm{C} \mathrm{CP}$ (cross polarisation) MAS NMR spectra were acquired at $25{ }^{\circ} \mathrm{C}$ using spinning rates of 5 or $10 \mathrm{kHz}$. Due to the long pulse delay (180 s) of the reacting compounds, spectra of sufficient quality could only be acquired over a period of 6 hours after 128 scans. Five or three experiments for each spinning rate were carried out over a period of 30 hours in the case of pre-milled materials and 18 hours for physical mixtures, as no changes after this time were observed (Figs. S6 and S7 in Supporting Information). The resulting solid-state NMR spectra show the average pictures of the structural and dynamical processes taking place during cocrystallisation of isoniazid and benzoic acid in the six-hour time intervals.

Solid-state NMR analysis. Solid-state NMR spectra were acquired using a Bruker AVANCE III spectrometer equipped with a $4 \mathrm{~mm}$ triple resonance probe at $400.23 \mathrm{MHz}$ for ${ }^{1} \mathrm{H}$ and 100.64 $\mathrm{MHz}$ for ${ }^{13} \mathrm{C}$. The ${ }^{1} \mathrm{H}-{ }^{13} \mathrm{C}$ cross-polarization/magic angle spinning (CP/MAS) NMR spectra were acquired using a RAMP CP pulse sequence. The MAS rates were 5 or $10.0 \mathrm{kHz} ;{ }^{1} \mathrm{H} \pi / 2$ pulse 
length and pulse delay were optimized to $3.20 \mu \mathrm{s}$ and $180.0 \mathrm{~s}$, respectively. The contact time during $\mathrm{CP}$ was set to $2.0 \mathrm{~ms}$ and a SPINAL64 decoupling was applied during acquisition. The HartmannHahn conditions ${ }^{59}$ were set with hexamethylbenzene (HMB). 512 scans were acquired for pure crystalline compounds and 128 during cocrystallisation experiments. The ${ }^{13} \mathrm{C}$ chemical shifts were recorded with respect to tetramethylsilane (TMS).

Analysis of the cocrystallisation kinetics under MAS conditions. The spectra were deconvoluted using a Gaussian-shape fitting function using Fityk 0.9.8. ${ }^{60}$ and integrated peak areas were compared for both MAS rates. Comparison of the cocrystallisation kinetics of isoniazid and benzoic acid at MAS rates of 5 and $10 \mathrm{kHz}$ was based on the intensity of the peak at $172.3 \mathrm{ppm}$, which is attributed to the carbonyl group of benzoic acid.

DVS analysis. The water vapour sorption-desorption isotherms of isoniazid and benzoic acid 1:1 physical mixture were measured with a TA Q5000 SA instrument at 30, 40 and $50{ }^{\circ} \mathrm{C}$. The relative humidity was increased with a step size of 5\% from 5\% to $95 \%$ RH and decreased to $5 \%$ $\mathrm{RH}$ again. The dwell time at each RH was $1 \mathrm{~h}$. The sample was dried at $60^{\circ} \mathrm{C}$ for 1 hour prior to analysis.

Scanning electron microscopy (SEM). The particle size and morphology of isoniazid, benzoic acid and the cocrystal were analysed using scanning electron microscopy (SEM) using a JEOL JSM-5910 LV SEM Scanning Electron Microscope with an accelerating voltage of $20 \mathrm{kV}$. The working distance was $9 \mathrm{~mm}$. The samples were sputtered with gold in an argon atmosphere at room temperature before examination.

Hot stage microscopy (HSM). Formation of the isoniazid-benzoic acid cocrystal upon heating (at $90{ }^{\circ} \mathrm{C}$ ) was followed using a Leica DM LS2 optical microscope, equipped with the Mettler Toledo FP 82 HT hot stage and FP 90 temperature controller. The microscope was also used to observe the sublimation of smaller benzoic acid crystals at ambient conditions (45-55\% RH and $20-22^{\circ} \mathrm{C}$ ) for 20 hours.

AFM analysis. The AFM height images $(25 \mu \mathrm{m} \times 25 \mu \mathrm{m})$ and force measurements were recorded in QI mode (Quantitative Imaging mode ${ }^{61}$ ) at room temperature in air at a resolution of $256 \times 256$ pixels using the NanoWizard 3 (JPK Instruments AG) AFM system. The maximum force determined by the vertical deflection of the cantilever (i.e., setpoint) was set to $0.7^{-1} \mathrm{nN}$, and the scan rates were automatically controlled by the $\mathrm{Z}$ length $(1 \mu \mathrm{m})$, extension time $(5 \mathrm{~ms})$ and retraction time $(5 \mathrm{~ms})$. Soft cantilevers (NanoWorld Arrow-Cont) were used and the typical force constant of the cantilever was $0.2 \mathrm{~N} \mathrm{~m}^{-1}$. The force constant for each of the cantilevers was calibrated using the thermal noise method. ${ }^{62}$ For the in situ AFM humidity studies an enclosure was constructed and the humidity inside the enclosure was followed by a Fischer Scientific Humidity/Temperature Pen. For each change in humidity the sample was allowed to equilibrate for 
at least 48 hours.

FTIR analysis. The FTIR spectra were recorded using a Perkin Elmer Spectrum BX instrument in the range $550-4000 \mathrm{~cm}^{-1}$ with a resolution of $2 \mathrm{~cm}^{-1}$. Each spectrum was generated by co-addition of 64 interferograms.

\section{Results and Discussion}

Our initial intention was to analyse the kinetics of the mechanochemical cocrystallisation of isoniazid and benzoic acid, however direct monitoring of the process was hampered by continuation of the reaction after stopping the milling. The kinetics of cocrystal formation in these pre-milled samples was found to depend on the milling frequency and on the conditions (temperature, humidity) of sample storage. These observations have important implications on the quality of kinetic data analysis, so cocrystallisation in pre-milled samples was studied at various temperatures and humidity; and the cocrystallisation rate in milled samples was compared to that in unmilled physical mixtures. The kinetics of cocrystallisation was followed using in-situ powder X-ray diffraction (PXRD) and complementary data were obtained by solid-state NMR and IR spectroscopy. In addition scanning electron microscopy (SEM), atomic force microscopy (AFM) and dynamic vapour sorption (DVS) were employed to obtain qualitative information about the mechanism of cocrystallisation and to understand the involvement of water vapour in this reaction.

Structural considerations of the isoniazid-benzoic acid cocrystal. Cocrystallisation proceeds through the disintegration of the isoniazid and benzoic acid crystal structures, followed by the emergence of a cocrystal. These processes were studied by structural characterisation methods, such as solid-state NMR, FTIR and XRD. The FTIR spectrum of the physical mixture of isoniazid and benzoic acid is a superposition of the individual component spectra, showing no interactions between these compounds (Figure 1a). 


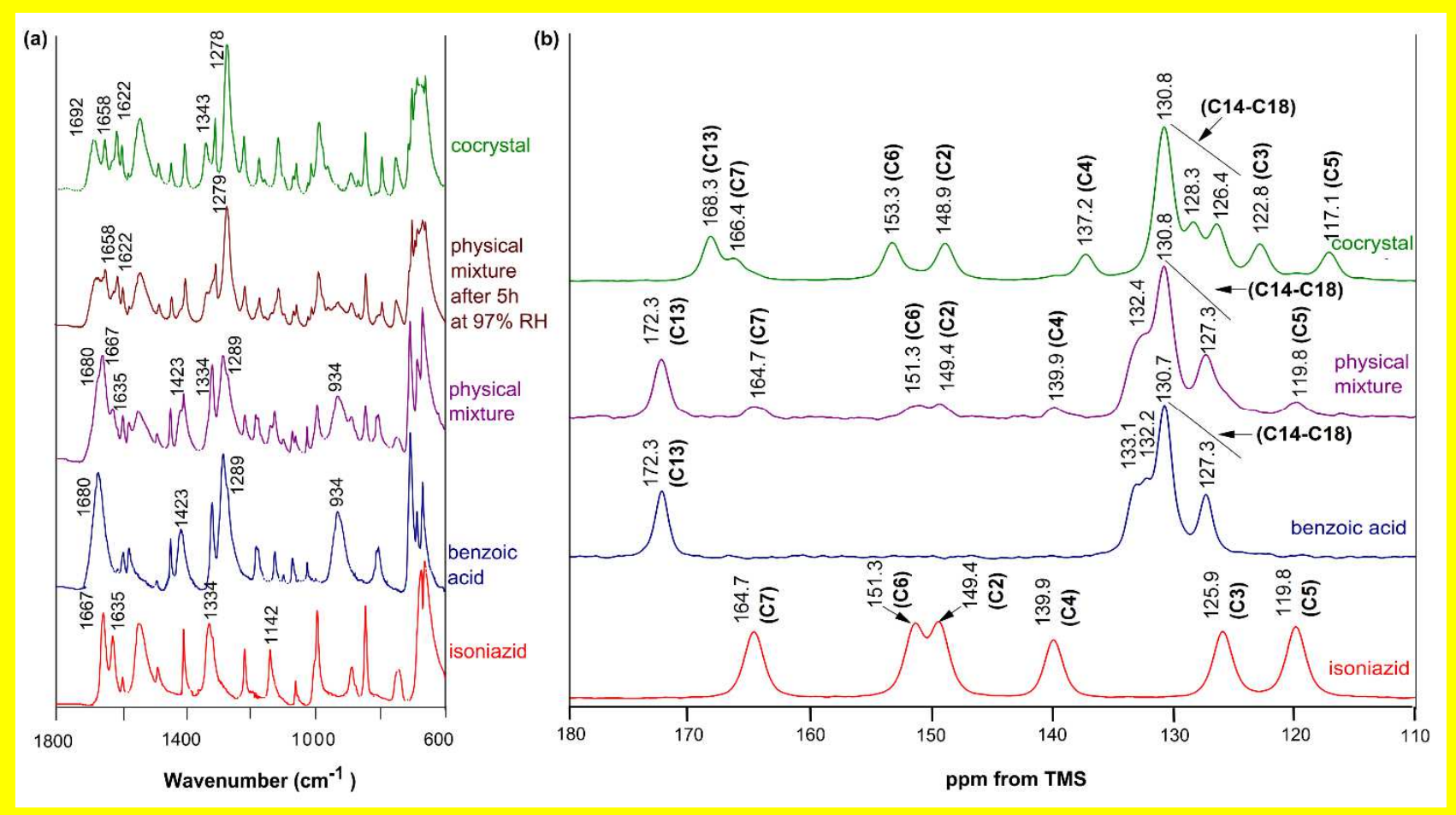

Figure 1. FTIR spectra of isoniazid, benzoic acid, their physical mixture, the physical mixture after $5 \mathrm{~h}$ at $40{ }^{\circ} \mathrm{C}$ and $c a .97 \% \mathrm{RH}$ and their cocrystal (a) and ${ }^{1} \mathrm{H}-{ }^{13} \mathrm{C} \mathrm{CP}$ MAS solid-state NMR spectra of isoniazid, benzoic acid, their physical mixture and cocrystal acquired at a MAS rate of 10 kHz (b). The NMR peak assignments refer to labels in Figure 2.

However, when the physical mixture was stored at elevated humidity, the FTIR bands characteristic to isoniazid and benzoic acid gradually disappeared and the new distinctive cocrystal bands appeared in the spectra (Figure S1 in Supporting Information).

The most pronounced changes observed in these FTIR spectra are related to functional groups that are involved in hydrogen bonding: the carboxyl group of benzoic acid, the pyridine ring and the hydrazide group of isoniazid. These changes in interactions are illustrated by the comparison of the crystal structure of the isoniazid-benzoic acid cocrystal ${ }^{53}$ with the structures of its constituents (Figure S2 in Supporting Information). For example, the comparison of structures revealed that the $C(3)$ hydrogen bonding chain between the hydrazide groups in isoniazid is retained in the crystal structure of the cocrystal. Meanwhile, the $\mathrm{N}-\mathrm{H} \cdots \mathrm{N}$ hydrogen bonds between the hydrazide and pyridine groups in isoniazid are broken, allowing new hydrazide-hydrazide $R_{2}^{2}(10)$ synthons to 
form in the cocrystal. The asymmetric unit of the cocrystal and the atom numbering scheme used throughout this account are given in Figure 2.

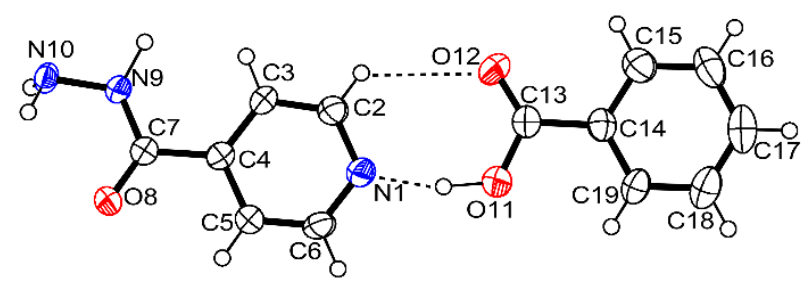

Figure 2. Asymmetric unit and atom numbering scheme of isoniazid-benzoic acid cocrystal.

Similarly to the FTIR results, the ${ }^{1} \mathrm{H}-{ }^{13} \mathrm{C}$ CP MAS solid-state NMR spectrum of the physical mixture of isoniazid and benzoic acid shows an overlay of the individual spectra of these compounds, while in the spectrum of the cocrystal considerable changes in the positions of peaks are observed (Figure 1b), implying changes in the molecular environment resulting from cocrystallisation. A detailed comparison of the FTIR and solid-state NMR spectra and the crystal structures of isoniazid, benzoic acid and their cocrystal is presented in the Supporting Information.

Kinetics of the mechanochemical cocrystallisation of isoniazid and benzoic acid. The cocrystallisation of isoniazid and benzoic acid can easily be achieved through mechanochemical treatment. However, when mechanochemistry is used to obtain cocrystals, milling frequency becomes one of the most important factors determining the rate of the conversion ${ }^{32}$ and, consequently, the composition of the product. The influence of milling frequency on the mechanochemical cocrystallisation rate of isoniazid with benzoic acid was investigated via kinetic experiments at 20, 25 and $30 \mathrm{~Hz}$. The milling was performed for various time periods and the composition of the product for each milling experiment (Figure 3) was determined using Rietveld analysis of the PXRD patterns. 


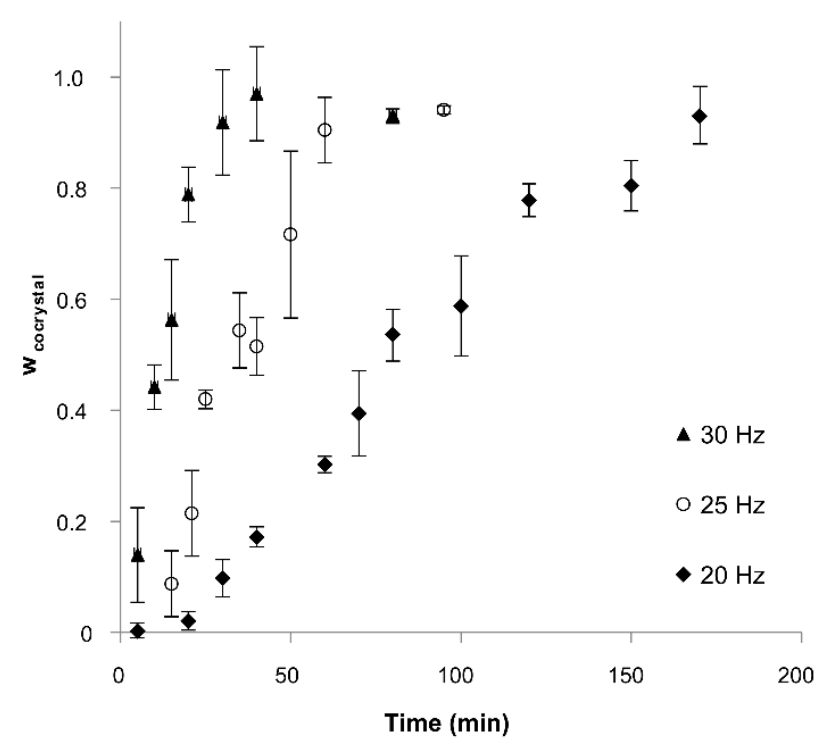

Figure 3. Conversion fraction $\mathrm{w}_{\text {cocrystal }}$ as a function of time for isoniazid - benzoic acid mechanochemical cocrystallisation at 20, 25 and $30 \mathrm{~Hz}$.

The impact of the frequency is illustrated by several times faster cocrystallisation at $30 \mathrm{~Hz}$ compared to $20 \mathrm{~Hz}$. The initial rate of cocrystal formation $\frac{d w}{d t}$ for milling at $30 \mathrm{~Hz}$ was about $4.1 \%$ $\min ^{-1}$, while for $20 \mathrm{~Hz}$ it was $0.7 \% \mathrm{~min}^{-1}$. The accelerating effect of a higher milling frequency on the reaction rate has been shown before ${ }^{32}$ and is related to better mixing of the reactants and removal of the product from the reactant interface. Furthermore, milling with a higher frequency may introduce higher energy to the reaction system by creating crystal defects, strains and reducing the average particle size ${ }^{28,29}$. A higher density of defects in the crystallites would consequently lead to a larger amount of possible nucleation sites. The relevance of nucleation sites created during milling is also confirmed by the decrease of induction times with increasing milling frequency. The induction time (extrapolated intersection of the $w_{\text {cocrystal }}$ curve with the time axis) for the reaction at $20 \mathrm{~Hz}$ was $c a .17 \mathrm{~min}$, while at $25 \mathrm{~Hz}$ it was $c a .10 \mathrm{~min}$ and at $30 \mathrm{~Hz}$ - only about 2-3 min.

In addition, milling in the ball mills creates a time dependent temperature gradient as a result of friction. The higher is the milling frequency, the higher temperature is achieved. For example, the temperature during milling at our typical experimental conditions for $200 \mathrm{~min}$ with $30 \mathrm{~Hz}$ reached $49-51^{\circ} \mathrm{C}$ while it reached only $33-34{ }^{\circ} \mathrm{C}$ during milling for $200 \mathrm{~min}$ at $20 \mathrm{~Hz}$. The increase 
of the temperature during the reaction increases the vapour pressure of benzoic acid, which undergoes sublimation, therefore uniform experimental conditions are not maintained through the experiment. The vapour pressure of benzoic acid increases exponentially with the temperature. ${ }^{63}$ It proved difficult to achieve a complete conversion to a cocrystal and a loss of benzoic acid from the solid samples was observed. Both observations may be attributed to an equilibrium between solid and gas phase benzoic acid:

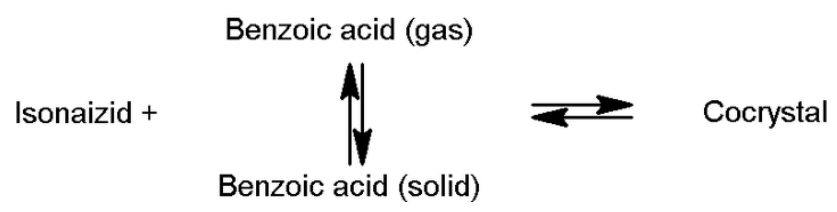

Scheme 1. A schematic representation of the isoniazid - benzoic acid cocrystallisation reaction

The effect of RH on the rate of cocrystallisation in pre-milled mixtures. Analysis of the milling products of isoniazid and benzoic acid showed that cocrystallisation in these samples continued after stopping the mechanical treatment and its rate depended on relative humidity. Samples milled for 5 minutes with 20 and $25 \mathrm{~Hz}$ frequency were chosen for further analysis, since no observable conversion to cocrystal occurred at these milling conditions (Figure 3). The impact of the humidity on the rate of cocrystallisation was investigated by storing such pre-milled samples at $60 \%, 70 \%$ and $80 \% \mathrm{RH}, 40{ }^{\circ} \mathrm{C}$ and recording sequential powder diffraction patterns. The amount of cocrystal in the sample as a function of time (Figure 4) was determined from the quantitative analysis of PXRD data. 


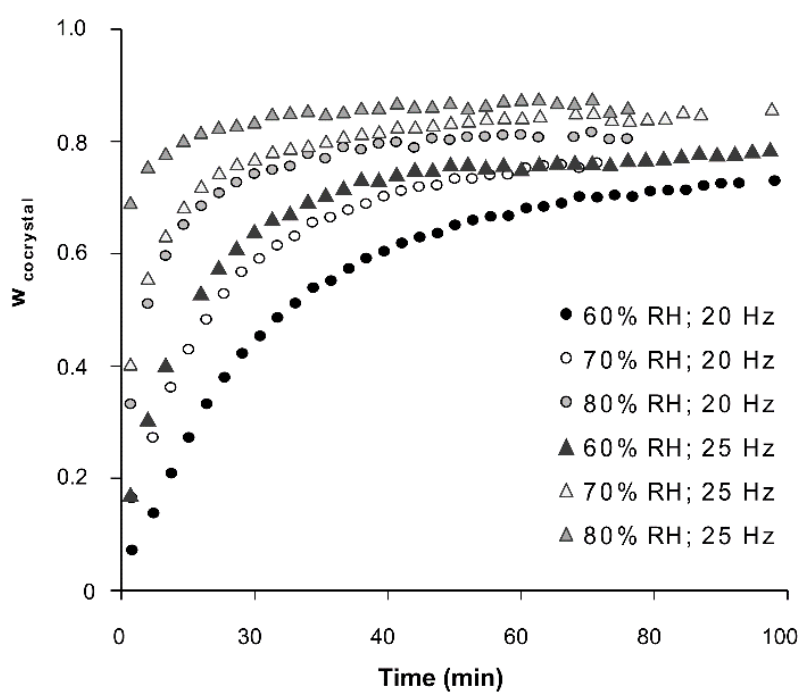

Figure 4. Conversion fraction $\mathrm{w}_{\text {cocrystal }}$ as a function of time in a pre-milled $(20 \mathrm{~Hz}$ and $25 \mathrm{~Hz}$ for $5 \mathrm{~min}$ ) isoniazid and benzoic acid mixture at $40^{\circ} \mathrm{C}$ and $60 \%, 70 \%$ and $80 \% \mathrm{RH}$.

The accelerating effect of increasing $\mathrm{RH}$ on the cocrystallisation kinetics implies that moisture facilitates the reaction. Since water is not included in the product crystal structure, it may serve as an intermediary solvent or as a plasticizer. At the early stages of the reaction the surface of the sample is readily available for the vapour and the reaction is facile and fast. However, the reaction slows down with an increasing amount of the product, which makes water access more difficult. Furthermore, as the amount of reactants in the sample decreases, the rate of cocrystal formation is reduced by the hampered migration of the reactants.

Since PXRD does not provide information on water uptake by the sample, the DVS method was used to observe the moisture sorption by physical mixtures of isoniazid and benzoic acid (Figure 5). The sorption-desorption isotherms at different temperatures $\left(30,40\right.$ and $\left.50{ }^{\circ} \mathrm{C}\right)$ do not show observable water sorption below $\mathrm{RH}=80 \%$. However, even very small (undetectable by DVS) amounts of water can plasticize the surface of crystallites and promote reactions at their interfaces. 


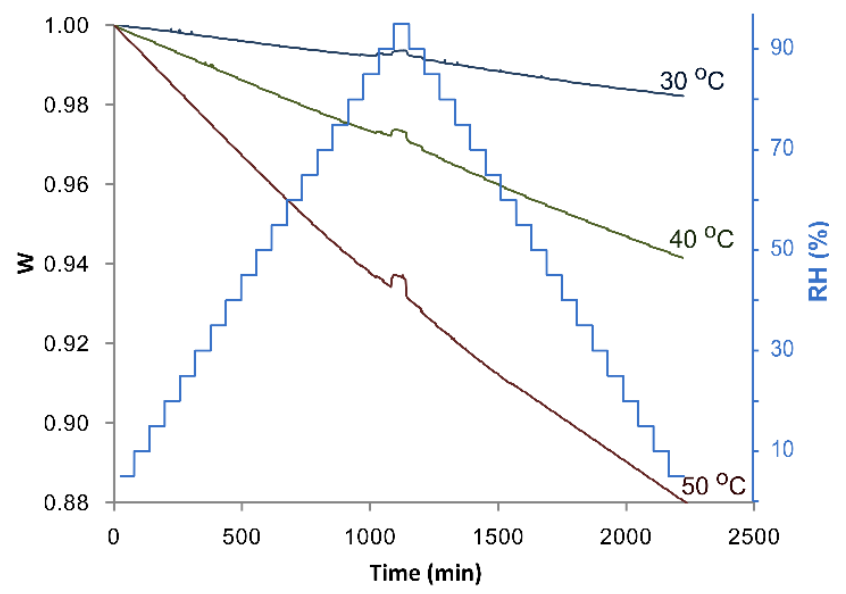

Figure 5. The water sorption - desorption isotherms of isoniazid and benzoic acid physical mixtures at 30,40 and $50{ }^{\circ} \mathrm{C}$. The blue line shows the relative humidity programme, the other lines indicate the relative weight of the samples (w) in reference to their initial, dry weight.

Interestingly, the DVS isotherms show a linear mass loss throughout the experiment resulting from the sublimation of benzoic acid even at temperatures as low as $30^{\circ} \mathrm{C}$. The temperature dependent vaporisation of benzoic acid implies that heating results in a higher vapour pressure which can lead to a faster reaction involving a gas phase reactant. Later, however, the loss of benzoic acid from the solid sample causes decomposition of the cocrystal as has been shown by our previous experiments. ${ }^{53}$

The surface reaction on isoniazid crystallites at elevated humidity. The DVS results indicate that moisture expedites the reaction by modifying surface properties rather than by partially dissolving the crystallites. In order to understand better the surface processes leading to cocrystallisation, the response of isoniazid surface to the presence of water and benzoic acid vapours was investigated using an atomic force microscope equipped with a custom-made humidity enclosure. Figure 6a shows AFM images of an isoniazid single crystal under ambient conditions $(50 \% \mathrm{RH})$ and after storing the same crystal at $78 \% \mathrm{RH}$ for two days, together with histograms of the height distributions for each image. 
(a)

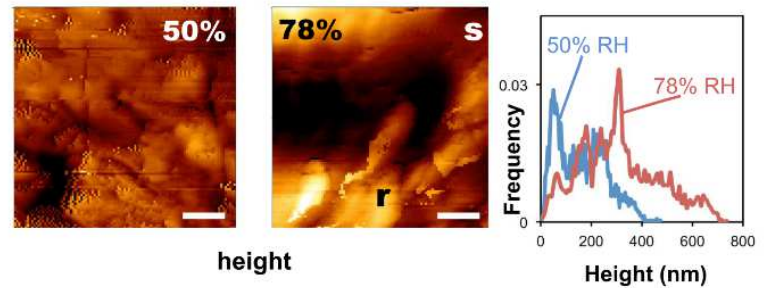

(b)
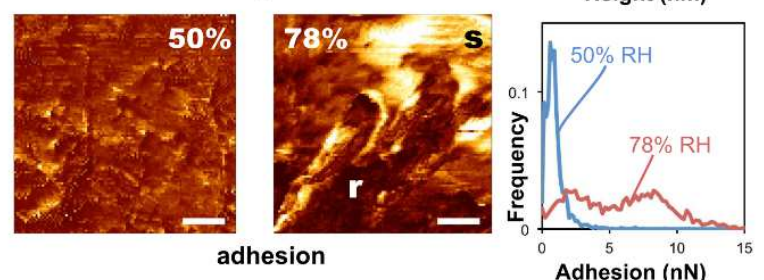

(c)

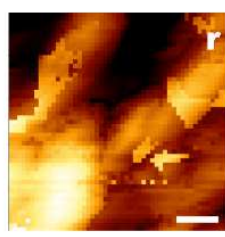

$\mathbf{s}$

(d)

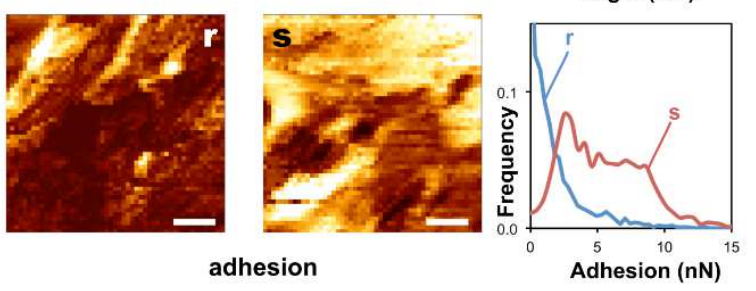

Figure 6. AFM height (a) and adhesion (b) images and histograms of height and adhesion values in the image data, of isoniazid crystal surface at $50 \%$ and $78 \% \mathrm{RH}$. Scale bar in each case is $2000 \mathrm{~nm}$; z-scales in the images are $500 \mathrm{~nm}$ and $6 \mathrm{nN}$ for the $50 \% \mathrm{RH}$ images and $1000 \mathrm{~nm}$ and 12 $\mathrm{nN}$ for the $78 \% \mathrm{RH}$ images. Height (c) and adhesion (d) images and histograms of rough and smooth regions [corresponding to regions ' $r$ ' and ' $s$ ' in (a) and (b)] of the crystal surface after storage at $78 \%$ RH. Scale bar in each case is $1000 \mathrm{~nm}$; z-scales are $500 \mathrm{~nm}$ and $12 \mathrm{nN}$.

The height images show that the isoniazid crystal under ambient conditions presents a rough $($ mean height $=172 \mathrm{~nm}$, r.m.s. roughness $=63 \mathrm{~nm})$ surface with salient features. Since the salient formations were not displaced by the tip of the AFM cantilever they were assumed to be characteristic to the crystal surface. After storing the same crystal at $78 \% \mathrm{RH}$ for two days, the AFM images show increased surface heterogeneity, with a greater overall roughness (mean height $=$ $310 \mathrm{~nm}$, r.m.s. roughness $=190 \mathrm{~nm}$ ), but including prominent areas where the surface is much 
smoother. It has been reported elsewhere ${ }^{64}$ that water adsorption at elevated humidity leads to reordering and smoothing of the crystal surface for cocrystal materials.

Figure $6 \mathrm{~b}$ shows adhesion maps obtained using the QI mode of the AFM for the same areas as presented in Figure 6a. These maps show that there is a significant increase in adhesion of the AFM probe to the crystal at higher humidity, with the mean adhesion increasing from $0.74 \mathrm{nN}$ (r.m.s. adhesion $=0.66 \mathrm{nN}$ ) to $2.96 \mathrm{nN}$ (r.m.s. adhesion $=2.57$ ). Both height distribution and the adhesion distribution for the sample imaged at high humidity exhibits much greater heterogeneity, with regions having adhesion similar to the ambient case alongside regions with much higher adhesion. The regions of high adhesion appear to be those with decreased roughness. In the height and adhesion images of the high humidity sample we have labelled two regions 's' and ' $r$ ' for 'smooth' and 'rough', and Figures $6 \mathrm{c}$ and $6 \mathrm{~d}$ present height and adhesion maps of those areas. The histograms corroborate our initial observations and demonstrate that those are the smooth regions $($ mean height $=597 \mathrm{~nm}$, r.m.s. roughness $=58 \mathrm{~nm})$ that have high adhesion $($ mean adhesion $=5.71$ $\mathrm{nN}$, r.m.s. adhesion $=3.23 \mathrm{nN}$ ), consistent with the interpretation that the smoothed regions are the result of water sorption by the crystal.

To test if a surface reaction of isoniazid with benzoic acid vapour could take place, a crystal of benzoic acid was placed in a close proximity to an isoniazid crystal. AFM images were recorded, after at least $48 \mathrm{~h}$ equilibration, for the isoniazid crystal at ambient conditions $(50 \% \mathrm{RH}$, $\left.24{ }^{\circ} \mathrm{C}\right)$, low humidity $\left(28 \% \mathrm{RH}, 24{ }^{\circ} \mathrm{C}\right)$ and elevated humidity $\left(83 \% \mathrm{RH}, 26{ }^{\circ} \mathrm{C}\right)$. The AFM images at ambient and low humidity do not show considerable differences in the isoniazid surface morphology (Figure 7) and the same features can be identified. 
(a) height
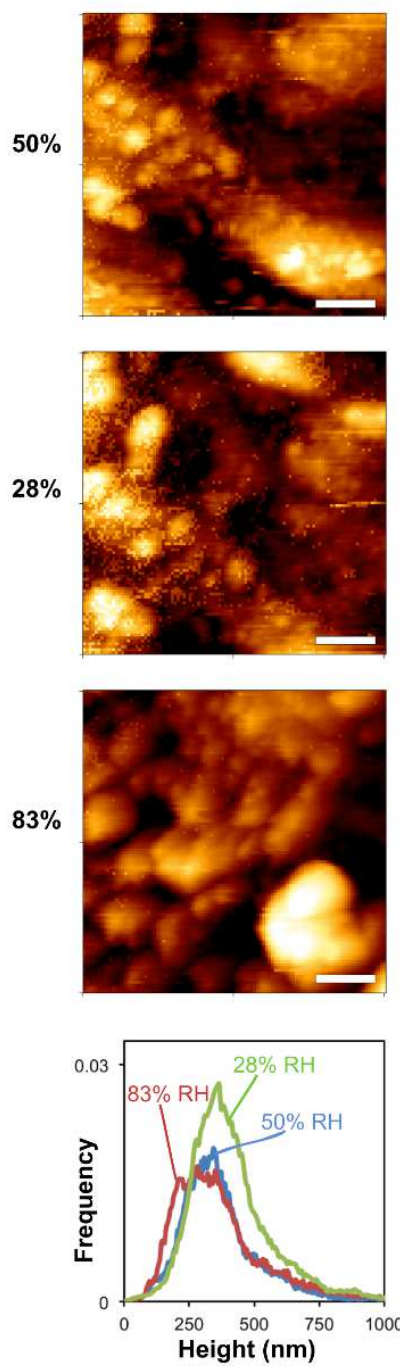

(b) adhesion
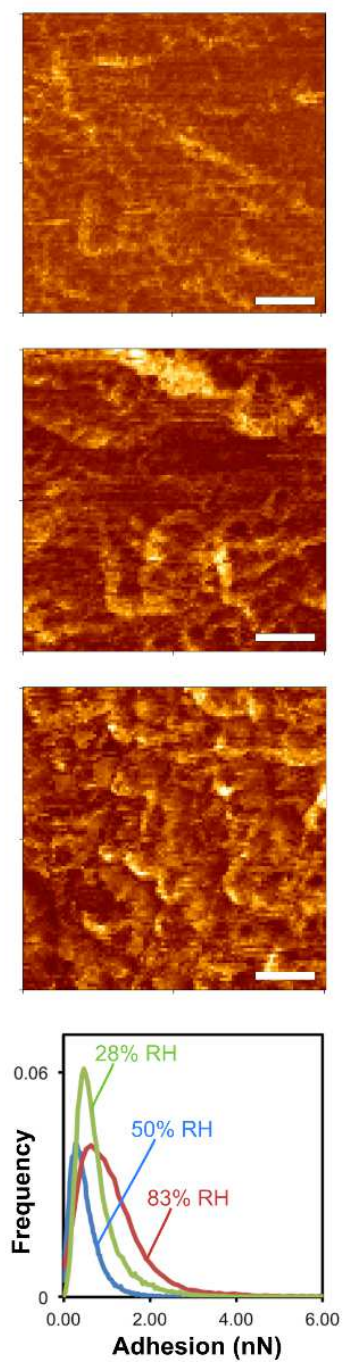

Figure 7. AFM height (a) and adhesion (b) images and histograms of height and adhesion values in the image data of isoniazid crystal surface in the presence of benzoic acid at $50 \%, 28 \%$ and $83 \%$ RH. Scale bar in each case is $2000 \mathrm{~nm}$; z-scales are $1000 \mathrm{~nm}$ and $6 \mathrm{nN}$.

The height and adhesion values for measurements at these conditions were also similar (mean heights 416 and $389 \mathrm{~nm}$, r.m.s. roughnesses 95 and $73 \mathrm{~nm}$; mean adhesions 0.49 and $0.81 \mathrm{nN}$, r.m.s. adhesions 0.37 and $0.54 \mathrm{nN}$, respectively). At elevated humidity (83\% $\mathrm{RH})$, however, new more pronounced salient formations on the surface of isoniazid were observed. The adhesion of the surface in the high humidity experiment was found to be slightly higher (mean adhesion $=1.17$, r.m.s. adhesion $=0.88 \mathrm{nN}$ ) compared to adhesion at low and ambient humidity. These observations 
imply that at elevated humidity the adsorption of water promotes molecular rearrangements in the surface layer. In the absence of benzoic acid this results in recrystallization of the crystal surface. In the presence of benzoic acid, however, the moisture facilitates the reaction with benzoic acid as it vaporizes and is deposited on the surface of the isoniazid crystal. Therefore, a cocrystallisation of two compounds appears possible even without direct contact between their crystallites. Similar observations have been reported for halogen bonding systems, which formed cocrystals via physical vapour deposition. ${ }^{65}$

Effect of temperature on the rate of isoniazid - benzoic acid cocrystallisation. Another parameter that can significantly influence the rate of cocrystal formation is temperature. In the case of the isoniazid and benzoic acid cocrystal, increasing temperature not only supplies more energy, but also raises the vapour pressure of benzoic acid. Both the reaction rate and the degree of vaporization can be deduced from variable temperature PXRD experiments. Kinetic data were acquired for pre-milled $(5 \mathrm{~min}, 20 \mathrm{~Hz})$ samples at $35,40,45,50$ and $55^{\circ} \mathrm{C}$ (Figure 8).

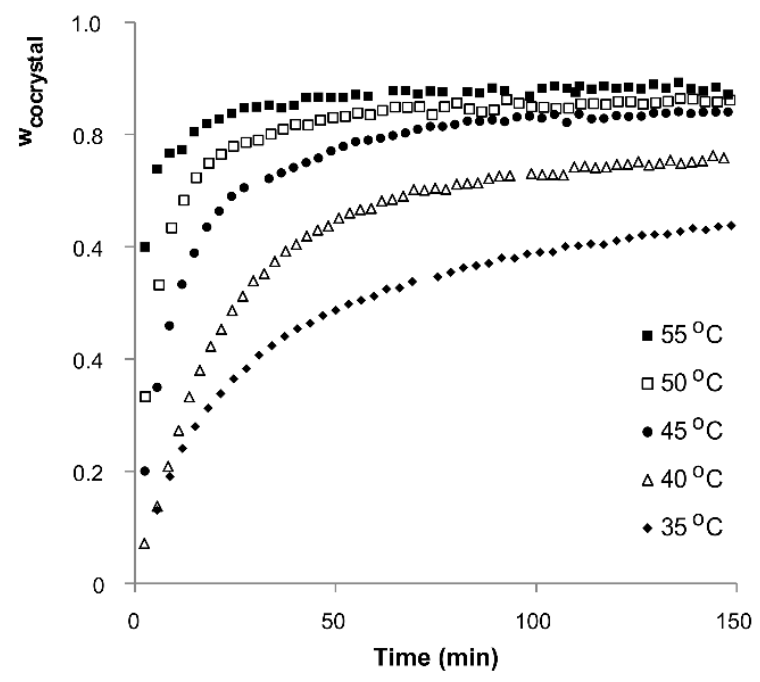

Figure 8. Conversion fraction $\mathrm{w}_{\text {cocrystal }}$ as a function of time for isoniazid-benzoic acid cocrystal formation from pre-milled mixtures $(20 \mathrm{~Hz}, 5 \mathrm{~min})$ at $35,40,45,50$ and $55{ }^{\circ} \mathrm{C}$ temperature and $60 \% \mathrm{RH}$. 
The kinetic data presented in Figure 8 confirm the significant effect of temperature on cocrystallisation kinetics and show that the initial rates $\left(\frac{d w}{d t}\right)$ increase exponentially with temperature (Figure S3 in Supporting Information). The vaporisation of benzoic acid during the reaction is confirmed by a lower crystalline acid content (mol \%) compared to isoniazid in all cocrystallisation experiments (Figure S4 in Supporting Information, determined by PXRD). Isoniazid reacts with benzoic acid in the stoichiometric ratio of $1: 1$, so in the absence of benzoic acid vaporisation the amount of both compounds would decrease equally. The kinetic experiments discussed above were performed at $\mathrm{RH}=60 \%$. To investigate if the formation of the cocrystal can take place without the assistance of water vapour, further experiments in dry air were performed.

Pre-milled $(20 \mathrm{~Hz}, 5 \mathrm{~min})$ isoniazid and benzoic acid 1:1 mixtures were placed in desiccators with $\mathrm{P}_{2} \mathrm{O}_{5}$ at 30,50 and $70{ }^{\circ} \mathrm{C}$ temperature. It was found that the cocrystallisation takes place even at $0 \% \mathrm{RH}$, as shown by PXRD patterns recorded for pre-milled mixtures after keeping samples at these conditions for $24 \mathrm{~h}$ (Figure 9).

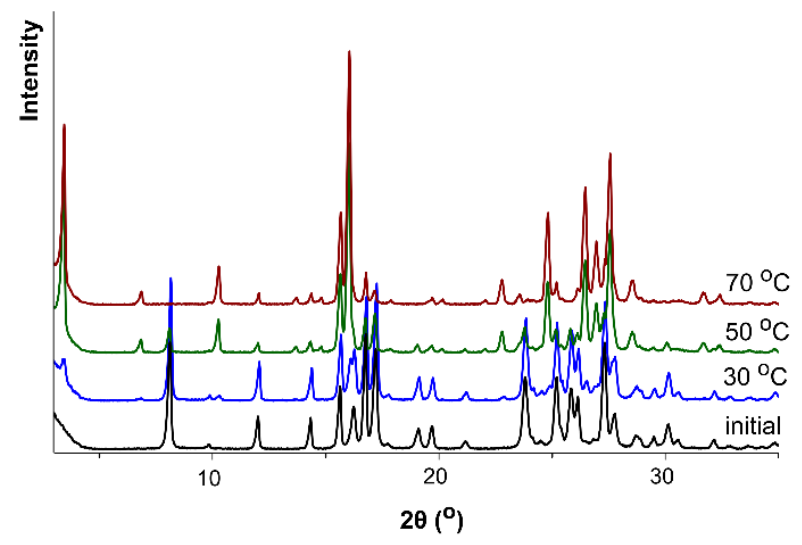

Figure 9. PXRD patterns of isoniazid-benzoic acid 1:1 milled $(20 \mathrm{~Hz}, 5 \mathrm{~min})$ mixture before and after storing at $0 \% \mathrm{RH}$ and $30^{\circ} \mathrm{C}, 50{ }^{\circ} \mathrm{C}$ and $70{ }^{\circ} \mathrm{C}$ temperature for $24 \mathrm{~h}$.

The cocrystal content in the sample after storage at $30^{\circ} \mathrm{C}$ for $24 \mathrm{~h}$ was $12 \%$ while at $50{ }^{\circ} \mathrm{C}$ the cocrystal content in the sample reached $76 \%$. At $70{ }^{\circ} \mathrm{C}$ a full conversion was achieved. A small amount of excess isoniazid, however, was found to be present in the latter sample, because part of 
benzoic acid had vaporized. These experiments show that cocrystallisation is possible without the presence of water vapour; however, it is slow at ambient temperatures compared to reactions at elevated humidity. During longer storage periods (more than 1 week) a decrease in the amount of cocrystal was observed, indicating decomposition of the cocrystal at $50{ }^{\circ} \mathrm{C}$ and $70{ }^{\circ} \mathrm{C}$. The presence of benzoic acid was not observed in the PXRD patterns of the decomposition product, suggesting that it vaporizes upon, or immediately after, decomposition.

Since at elevated temperature cocrystallisation can occur through eutectic melting ${ }^{31}$, hot stage microscopy experiments were conducted to assess this possibility. The HSM micrographs in Figure 10 show a stepwise depiction of the eutectic melting and the following cocrystallisation from melt.

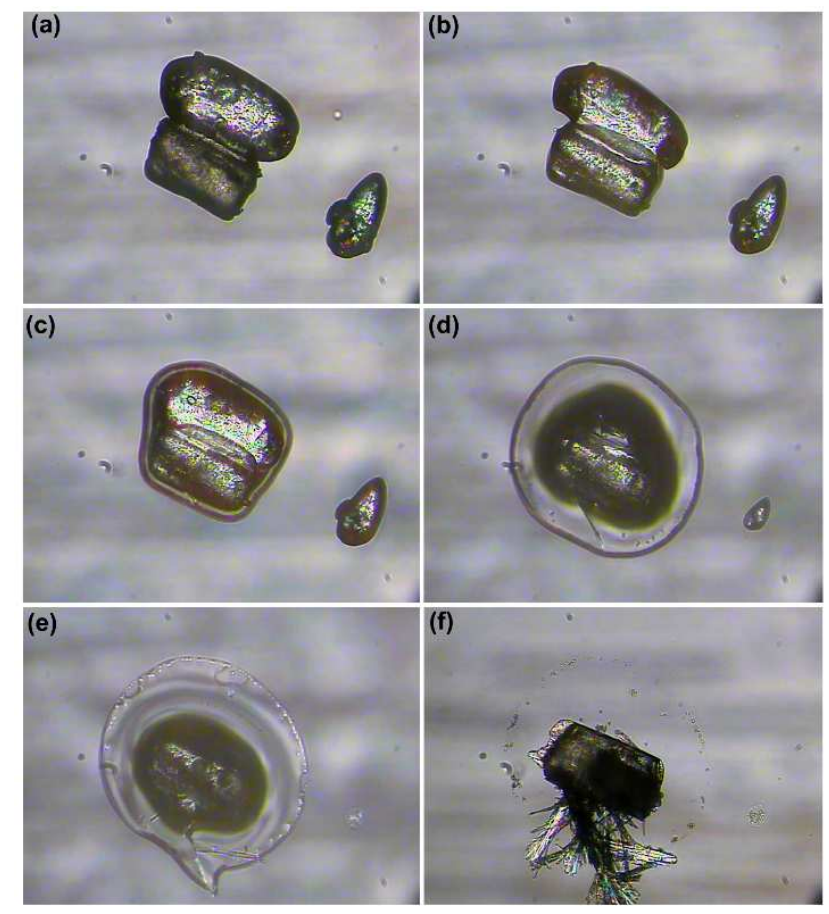

Figure 10. Cocrystal formation from the eutectic melt of isoniazid and benzoic acid at $90{ }^{\circ} \mathrm{C}$ after (a) $0 \mathrm{~min}$; (b) after $0.6 \mathrm{~min}$; (c) after $1.4 \mathrm{~min}$; (d) after $3.7 \mathrm{~min}$; (e) after $6.15 \mathrm{~min}$; (f) after 20 $\min$.

At $90^{\circ} \mathrm{C}$ a rapid formation of liquid phase around the cocrystal components was observed. After the eutectic melting, a new cocrystal recrystallizes from the melt. Since the eutectic melting 
takes place only at $90{ }^{\circ} \mathrm{C}$ the cocrystallisation during milling or temperature assisted experiments is not expected to occur through melting.

The effect of pre-milling frequency on the rate of isoniazid-benzoic acid cocrystallisation. The experiments conducted for pre-milled samples at elevated humidity showed that the frequency of pre-milling has a significant effect on the rate of cocrystallisation. The contribution of this parameter was investigated in detail by milling the reaction mixture for 5 minutes with various frequencies $(20,25$ and $30 \mathrm{~Hz})$ and measuring the cocrystallisation rate in the milling products at $40{ }^{\circ} \mathrm{C}$ and $60 \% \mathrm{RH}$ (Figure 11).

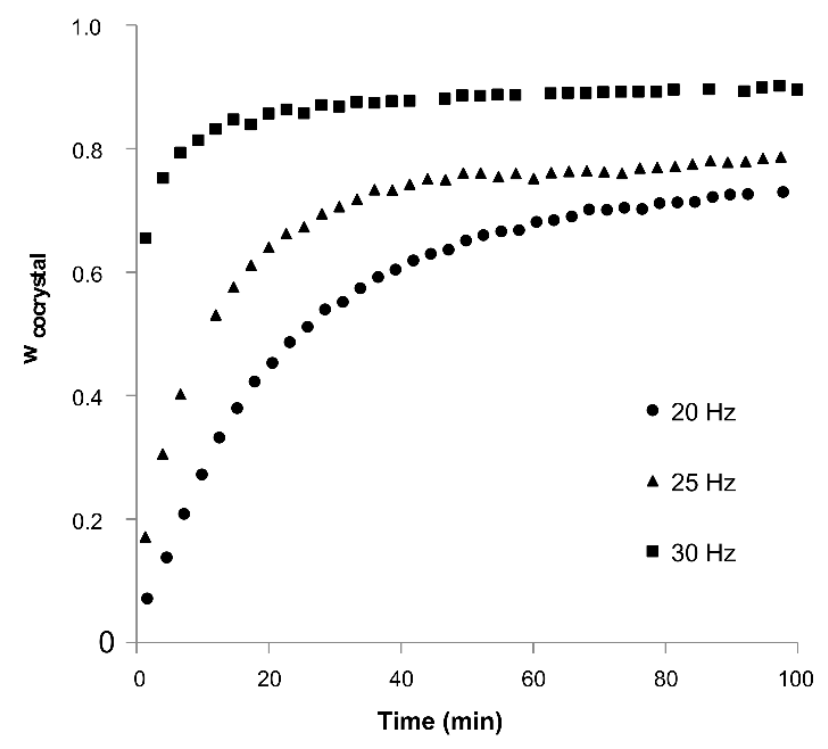

Figure 11. Conversion fraction $\mathrm{w}_{\text {cocrystal }}$ as a function of time for isoniazid-benzoic acid cocrystal formation from mechanochemically activated compounds at $40{ }^{\circ} \mathrm{C}$ and $60 \% \mathrm{RH}$ for various pre-milling frequencies $(20,25,30 \mathrm{~Hz})$.

The cocrystallisation in mechanically activated mixtures proceeds without an apparent induction time (Figures 4 and 8) implying that the nucleation of the cocrystal is initiated by milling. PXRD analysis of the fresh samples milled at 20 or $25 \mathrm{~Hz}$ for 5 min does not show detectable amounts of cocrystal and the sample milled at $30 \mathrm{~Hz}$ contains $\approx 14 \%$ cocrystal (Figure 1). After storing pre-milled samples in the humidity chamber their composition rapidly changes as the 
cocrystal is formed; and the higher has been the milling frequency, the faster is the conversion. The accelerating effect of milling is a result of reduced particle size, crystal defects, strains and mixing of the compounds. ${ }^{28,29}$ The higher is the frequency of milling, the smaller particle size and larger surface area are achieved. The changes in particle size and morphology introduced by milling to isoniazid and benzoic acid crystallites were observed using scanning electron microscopy (Figure 12).

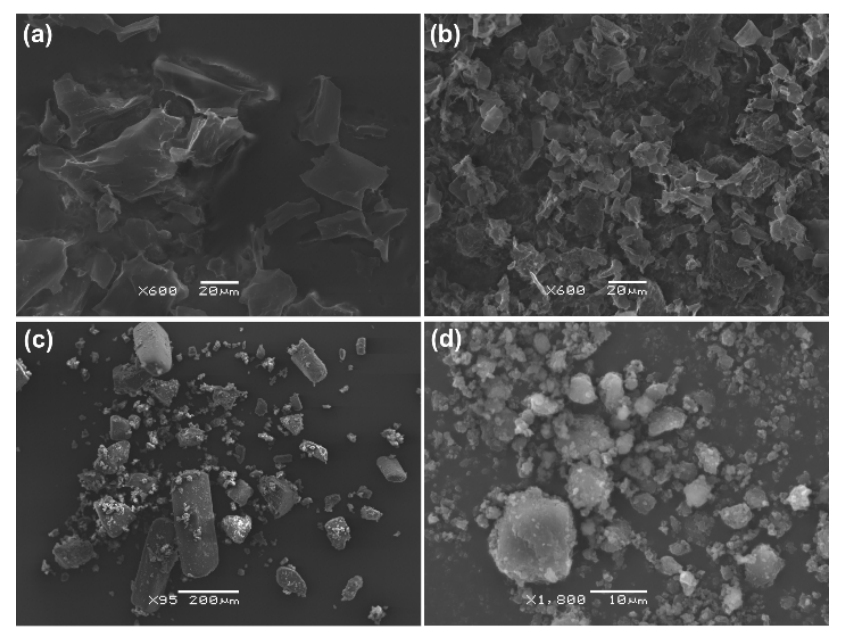

Figure 12. SEM images of (a) benzoic acid (75 - $150 \mu \mathrm{m}$ fraction); (b) benzoic acid after milling (30 Hz, $5 \mathrm{~min}$ ); (c) isoniazid (75 - $150 \mu \mathrm{m}$ fraction); (d) isoniazid after milling (30 Hz, 5 $\min )$.

Although only the $75-150 \mu \mathrm{m}$ fraction of sieved isoniazid and benzoic acid samples was used for all experiments, the particle size distribution of these samples varies in a wide range (Figure 12, a and c). As expected, milling reduces the average particle size in the sample (Figure 12, b and d). The crystallites no longer exhibit the distinct crystal habit characteristic to isoniazid and particle surfaces after milling appear rougher, indicating that surface defects may form during milling. A higher density of such defects after milling increases the sublimation rate ${ }^{66}$ of a compound. As benzoic acid tends to sublime, its vaporization behaviour after milling $(30 \mathrm{~Hz}, 5$ min) was observed using an optical microscope (Figure S5 in Supporting Information). The smaller 
crystallites gradually disappeared from the milled sample even at room temperature and their disappearance became obvious in less than 2 hours.

Cocrystallisation at elevated humidity without mechanical activation. Although a significant dependence of cocrystallisation rates on the pre-milling frequency was observed, it was not clear how fast these reactions were compared to the reaction in physical mixture.

In order to estimate the reaction rate in unmilled samples, 1:1 physical mixtures of isoniazid and benzoic acid were stored and maintained at $30{ }^{\circ} \mathrm{C}$ and $\mathrm{RH}$ of $38 \%, 58 \%, 75 \%, 84 \%$ and $97 \%$. Diffraction patterns of the samples were recorded periodically over a period of 27 days. Figure 13 shows the conversion fraction in these samples as a function of storage time.

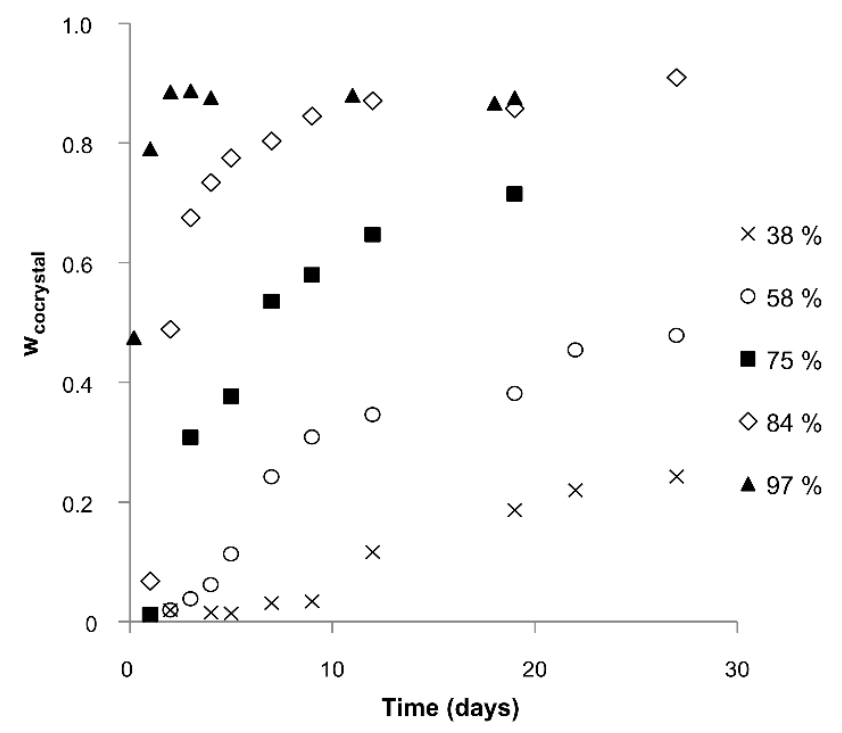

Figure 13. Conversion fraction $\mathrm{w}_{\text {cocrystal }}$ as a function of time for isoniazid-benzoic acid cocrystal formation in physical mixtures at various relative humidity $(38 \%, 58 \%, 75 \%, 84 \%$ and $97 \%)$ at $30{ }^{\circ} \mathrm{C}$.

The results of this experiment show that cocrystallisation without mechanical activation is considerably slower compared to cocrystal formation in a pre-milled mixture. Even at high RH values (above $84 \% \mathrm{RH}, 30{ }^{\circ} \mathrm{C}$ ), the cocrystallisation requires several days for the product yield to exceed $80 \%$, while it takes only about 1 hour for mechanically activated reactants at $80 \%$ RH (at 
$40{ }^{\circ} \mathrm{C}$ ). A significant induction time (several days) for these experiments is observed at lower RH values (lower than $75 \% \mathrm{RH}$ ). The slow cocrystallisation and the long induction time confirm the importance of mechanochemical treatment to initiate cocrystallisation and to activate reactants by introducing additional energy in the form of crystal defects ${ }^{67}$ and larger surface area. The cocrystallisation in physical mixtures and its rate dependence on relative humidity concur with the results of AFM experiments and suggest that the new phase formed on the surface of isoniazid crystals at elevated humidity in the presence of benzoic acid vapour was the cocrystal.

Kinetics of isoniazid-benzoic mechanochemical cocrystallisation under conditions of magic angle spinning. We used solid-state NMR to obtain molecular level details of cocrystallisation of isoniazid and benzoic acid. During these experiments an accelerating effect of magic angle spinning (MAS) on the cocrystallisation rate was observed. To estimate the extent of this effect, measurements at different MAS rates were performed and compared for both pre-milled and unmilled samples. The comparison was based on the intensity changes of the peak of the benzoic acid carboxyl group. This peak was selected, because the carbon of the carboxyl group does not have directly attached protons and therefore, intensities of the corresponding peaks are least affected by kinetics of the magnetization. ${ }^{68}$ The use of the MAS rate of $10 \mathrm{kHz}$ for the acquisition of ${ }^{1} \mathrm{H}-{ }^{13} \mathrm{C}$ CP/MAS NMR spectra of the mechanically activated mixture of benzoic acid and isoniazid lead to $\mathrm{ca} .50 \%$ decrease of the amount of benzoic acid in the reacting mixture after 30 hours. The decrease of benzoic acid content at the MAS rate of $5 \mathrm{kHz}$ was significantly lower - only $28 \%$ (Figure 14). These observations are corroborated by the increased intensity of the peaks attributable to the cocrystal and the decrease of isoniazid peak intensities (Figures S8 and S9, Tables S1 and S2 in the Supporting Information). In contrast, the unmilled physical mixture of isoniazid and benzoic acid showed no conversion into the cocrystal under either 5 or $10 \mathrm{kHz}$ MAS speed for over 18 hours (Figures S6 and S7 in Supporting Information). 


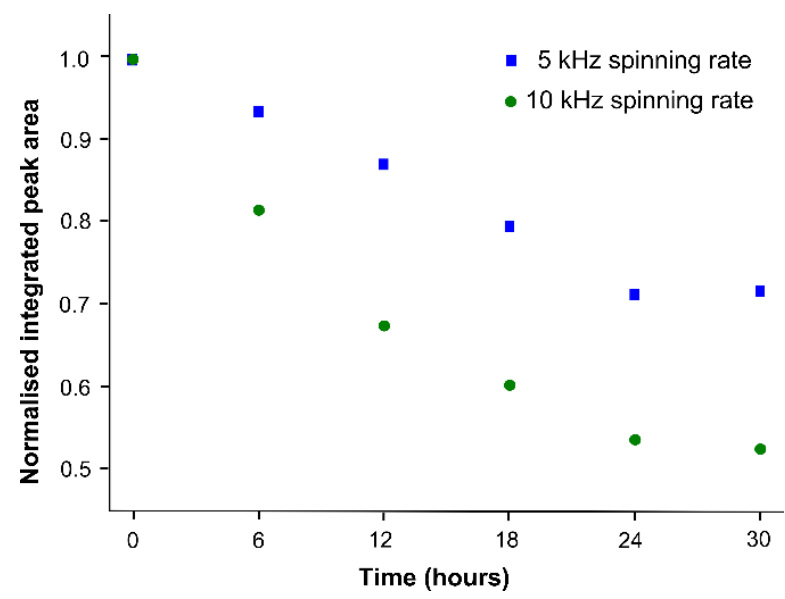

Figure 14. Comparison of the normalised peak intensity at $172.3 \mathrm{ppm}$ attributable to benzoic acid during cocrystallisation under MAS conditions at 5 and $10 \mathrm{kHz}$ spinning rates.

The impact of humidity and temperature changes on the cocrystallisation rate under MAS conditions was practically eliminated as each sample was spun in dry compressed air (dew point $80{ }^{\circ} \mathrm{C}$ ) in tightly sealed rotors and the experimental temperature was maintained at $25^{\circ} \mathrm{C}$. Similarly to other results discussed before these experiments confirm the promotive effect of mechanical treatment on cocrystallisation.

\section{Conclusions}

We have demonstrated a spontaneous cocrystallisation with a volatile compound, as illustrated by the reaction between isoniazid and benzoic acid. This reaction is accelerated by environmental conditions, such as elevated relative humidity or temperature and by mechanochemical activation. The rate and the mechanism of cocrystallisation are also influenced by the vaporisation of benzoic acid, as it undergoes temperature dependent sublimation. The results indicate that volatile solid compounds can initiate a surface reaction by first being deposited on the crystallites of the other cocrystal former. Such surface reactions benefit from the presence of moisture, which facilitates molecular movements via the adsorption of small amounts of water. Cocrystallisation is also enhanced by mechanical activation of the reaction mixture. The long 
induction time characteristic to cocrystallisation in physical mixtures was not observed for premilled samples, indicating that nucleation had taken place during the mechanical treatment. Therefore, an efficient method for the preparation of the isoniazid-benzoic acid cocrystal would include co-milling the cocrystal components (with an excess benzoic acid) and storing the product at elevated humidity for a short period of time to achieve complete conversion. The storage period should not exceed a couple of hours to avoid vaporisation of benzoic acid, which can lead to decomposition of the cocrystal.

This study expands the current understanding of heterogeneous supramolecular reactions and contributes to a better understanding of cocrystal formation, stability and decomposition. These are important to the design of stable drug formulations, as unpredicted spontaneous cocrystallisation or cocrystal decomposition can lead to changes in product composition, followed by implications on patient health. Meanwhile, a comprehensive understanding of these processes allows optimizing the experimental conditions and technologies for cocrystal preparation.

\section{Acknowledgements}

I.S. is grateful for the financial support of the ERASMUS programme. Authors also thank Mr. B. Leze for help in acquiring the SEM data.

\section{Supporting Information}

FTIR and solid-state NMR spectra, microscopy images, in-situ PXRD cocrystallisation data and initial rates of cocrystallisation. This material is available free of charge via the Internet at http://pubs.acs.org.

\section{References}

(1) Trask, A. V; Motherwell, W. D. S.; Jones, W. Physical Stability Enhancement of Theophylline via Cocrystallization. Int. J. Pharm. 2006, 320, 114-123.

(2) Tsutsumi, S.; Iida, M.; Tada, N.; Kojima, T.; Ikeda, Y.; Moriwaki, T.; Higashi, K.; Moribe, K.; Yamamoto, K. Characterization and Evaluation of Miconazole Salts and Cocrystals for Improved Physicochemical Properties. Int. J. Pharm. 2011, 421, 230-236. 
(3) Smith, A. J.; Kavuru, P.; Wojtas, L.; Zaworotko, M. J.; Shytle, R. D. Cocrystals of Quercetin with Improved Solubility and Oral Bioavailability. Mol. Pharm. 2011, 8, 1867-1876.

(4) McNamara, D. P.; Childs, S. L.; Giordano, J.; Iarriccio, A.; Cassidy, J.; Shet, M. S.; Mannion, R.; O’Donnell, E.; Park, A. Use of a Glutaric Acid Cocrystal to Improve Oral Bioavailability of a Low Solubility API. Pharm. Res. 2006, 23, 1888-1897.

(5) Arora, K. K.; Tayade, N. G.; Suryanarayanan, R. Unintended Water Mediated Cocrystal Formation in Carbamazepine and Aspirin Tablets. Mol. Pharm. 2011, 8, 982-989.

(6) Ibrahim, A. Y.; Forbes, R. T.; Blagden, N. Spontaneous Crystal Growth of Co-Crystals: The Contribution of Particle Size Reduction and Convection Mixing of the Co-Formers.

CrystEngComm 2011, 13, 1141-1152.

(7) Maheshwari, C.; Jayasankar, A.; Khan, N. a.; Amidon, G. E.; Rodríguez-Hornedo, N. Factors That Influence the Spontaneous Formation of Pharmaceutical Cocrystals by Simply Mixing Solid Reactants. CrystEngComm 2009, 11, 493-500.

(8) Jayasankar, A.; Good, D. J.; Rodríguez-Hornedo, N. Mechanisms by Which Moisture Generates Cocrystals. Mol. Pharm. 2007, 4, 360-372.

(9) Bag, P. P.; Reddy, C. M. Screening and Selective Preparation of Polymorphs by Fast Evaporation Method: A Case Study of Aspirin, Anthranilic Acid, and Niflumic Acid. Cryst. Growth Des. 2012, 12, 2740-2743.

(10) Kojima, T.; Tsutsumi, S.; Yamamoto, K.; Ikeda, Y.; Moriwaki, T. High-Throughput Cocrystal Slurry Screening by Use of in Situ Raman Microscopy and Multi-Well Plate. Int. J. Pharm. 2010, 399, 52-59.

(11) Aher, S.; Dhumal, R.; Mahadik, K.; Paradkar, A.; York, P. Ultrasound Assisted Cocrystallization from Solution (USSC) Containing a Non-Congruently Soluble Cocrystal Component Pair: Caffeine/maleic Acid. Eur. J. Pharm. Sci. 2010, 41, 597-602.

(12) Zhang, G. G. Z.; Henry, R. F.; Borchardt, T. B.; Lou, X. Efficient Co-Crystal Screening Using Solution-Mediated Phase Transformation. J. Pharamaceutical Sci. 2007, 96, 990-995.

(13) Horst, J. H.; Cains, P. W. Co-Crystal Polymorphs from a Solvent-Mediated Transformation. Cryst. Growth Des. 2008, 8, 2537-2542.

(14) Yu, Z. Q.; Chow, P. S.; Tan, R. B. H.; Ang, W. H. Supersaturation Control in Cooling Polymorphic Co-Crystallization of Caffeine and Glutaric Acid. Cryst. Growth Des. 2011, 11, 4525-4532.

(15) Childs, S. L.; Rodríguez-Hornedo, N.; Reddy, L. S.; Jayasankar, A.; Maheshwari, C.; McCausland, L.; Shipplett, R.; Stahly, B. C. Screening Strategies Based on Solubility and Solution Composition Generate Pharmaceutically Acceptable Cocrystals of Carbamazepine. CrystEngComm, 2008, 10, 856-864.

(16) Berry, D. J.; Seaton, C. C.; Clegg, W.; Harrington, R. W.; Coles, S. J.; Horton, P. N.; Hursthouse, M. B.; Storey, R.; Jones, W.; Friščić, T.; et al. Applying Hot-Stage Microscopy to Co-Crystal Screening: A Study of Nicotinamide with Seven Active Pharmaceutical Ingredients. Cryst. Growth Des. 2008, 8, 1697-1712. 
(17) Lu, E.; Rodríguez-Hornedo, N.; Suryanarayanan, R. A Rapid Thermal Method for Cocrystal Screening. CrystEngComm 2008, 10, 665-668.

(18) Padrela, L.; Rodrigues, M. A.; Velaga, S. P.; Fernandes, A. C.; Matos, H. A.; de Azevedo, E. G. Screening for Pharmaceutical Cocrystals Using the Supercritical Fluid Enhanced Atomization Process. J. Supercrit. Fluids 2010, 53, 156-164.

(19) Alhalaweh, A.; Velaga, S. P. Formation of Cocrystals from Stoichiometric Solutions of Incongruently Saturating Systems by Spray Drying. Cryst. Growth Des. 2010, 10, 33023305.

(20) Bysouth, S. R.; Bis, J. A.; Igo, D. Cocrystallization via Planetary Milling: Enhancing Throughput of Solid-State Screening Methods. Int. J. Pharm. 2011, 411, 169-171.

(21) Friščić, T.; Jones, W.; Fris, T. Recent Advances in Understanding the Mechanism of Cocrystal Formation via Grinding. Cryst. Growth Des. 2009, 9, 1621-1637.

(22) Trask, A. V; Motherwell, W. D. S.; Jones, W. Solvent-Drop Grinding: Green Polymorph Control of Cocrystallisation. Chem. Commun. 2004, 890-891.

(23) James, S. L.; Adams, C. J.; Bolm, C.; Braga, D.; Collier, P.; Friscic, T.; Grepioni, F.; Harris, K. D. M.; Hyett, G.; Jones, W.; et al. Mechanochemistry: Opportunities for New and Cleaner Synthesis. Chem. Soc. Rev. 2012, 41, 413-447.

(24) Loots, L.; Wahl, H.; van der Westhuizen, L.; Haynes, D. A.; le Roex, T. Interconversion between Different Stoichiometric Forms of a Three-Component Crystal via Liquid-Assisted Grinding. Chem. Commun. 2012, 48, 11507-11509.

(25) Karki, S.; Friščić, T.; Jones, W. Mechanochemistry and Cocrystals Control and Interconversion of Cocrystal Stoichiometry in Grinding: Stepwise Mechanism for the Formation of a Hydrogen-Bonded Cocrystal. CrystEngComm 2009, 11, 470-481.

(26) Cheng, W.-T.; Lin, S.-Y. Famotidine Polymorphic Transformation in the Grinding Process Significantly Depends on Environmental Humidity or Water Content. Int. J. Pharm. 2008, $357,164-168$.

(27) Michalchuk, A. A. L.; Tumanov, I. A.; Boldyreva, E. V. Complexities of Mechanochemistry: Elucidation of Processes Occurring in Mechanical Activators via Implementation of a Simple Organic System. CrystEngComm 2013, 15, 6403-6412.

(28) Delogu, F.; Deidda, C.; Mulas, G.; Schiffini, L.; Cocco, G. A Quantitative Approach to Mechanochemical Processes. J. Mater. Sci. 2004, 39, 5121-5124.

(29) Liu, X.; Liu, G.; Zhao, H.; Zhang, Z.; Wei, Y.; Liu, M.; Wen, W.; Zhou, X. The Quantitative Monitoring of Mechanochemical Reaction between Solid L-Tartaric Acid and Sodium Carbonate Monohydrate by Terahertz Spectroscopy. J. Phys. Chem. Solids 2011, 72, 12451250.

(30) Jayasankar, A.; Somwangthanaroj, A.; Shao, Z. J.; Rodríguez-Hornedo, N. Cocrystal Formation during Cogrinding and Storage Is Mediated by Amorphous Phase. Pharm. Res. 2006, 23, 2381-2392. 
(31) Chadwick, K.; Davey, R.; Cross, W. How Does Grinding Produce Co-Crystals? Insights from the Case of Benzophenone and Diphenylamine. CrystEngComm 2007, 9, 732-734.

(32) Ma, X.; Yuan, W.; Bell, S. E. J.; James, S. L. Better Understanding of Mechanochemical Reactions: Raman Monitoring Reveals Surprisingly Simple "Pseudo-Fluid" Model for a Ball Milling Reaction. Chem. Commun. 2014, 50, 1585-1587.

(33) Chieng, N.; Hubert, M.; Saville, D.; Rades, T.; Aaltonen, J. Formation Kinetics and Stability of Carbamazepine-Nicotinamide Cocrystals Prepared by Mechanical Activation. Cryst. Growth Des. 2009, 9, 2377-2386.

(34) Good, D.; Miranda, C.; Rodríguez-Hornedo, N. Dependence of Cocrystal Formation and Thermodynamic Stability on Moisture Sorption by Amorphous Polymer. CrystEngComm, 2011, 13, 1181-1189.

(35) Karki, S.; Friščić, T.; Jones, W.; Motherwell, W. D. S. Screening for Pharmaceutical Cocrystal Hydrates via Neat and Liquid-Assisted Grinding. Mol. Pharm. 2007, 4, 347-354.

(36) Cincić, D.; Friscić, T.; Jones, W. A Stepwise Mechanism for the Mechanochemical Synthesis of Halogen-Bonded Cocrystal Architectures. J. Am. Chem. Soc. 2008, 130, 7524-7525.

(37) Arhangelskis, M.; Lloyd, G. O.; Jones, W. Mechanochemical Synthesis of Pyrazine:dicarboxylic Acid Cocrystals and a Study of Dissociation by Quantitative Phase Analysis. CrystEngComm 2012, 14, 5203-5208.

(38) Shan, N.; Toda, F.; Jones, W. Mechanochemistry and Co-Crystal Formation: Effect of Solvent on Reaction Kinetics. Chem. Commun. 2002, 2372-2373.

(39) Friščić, T.; Halasz, I.; Beldon, P. J.; Belenguer, A. M.; Adams, F.; Kimber, S. a J.; Honkimäki, V.; Dinnebier, R. E. Real-Time and in Situ Monitoring of Mechanochemical Milling Reactions. Nat. Chem. 2013, 5, 66-73.

(40) Trask, A. V.; Motherwell, W. D. S.; Jones, W. Solvent-Drop Grinding: Green Polymorph Control of Cocrystallisation. Chem. Commun. 2004, 890-891.

(41) Kaur, R.; Perumal, S. S. R. R.; Bhattacharyya, A. J.; Yashonath, S.; Guru Row, T. N. Structural Insights into Proton Conduction in Gallic Acid-Isoniazid Cocrystals. Cryst. Growth Des. 2014, 14, 423-426.

(42) Chiya, T. J.; Lemmerer, A. Stoichiometric Variation in Two Molecular Salts of the AntiTuberculosis Drug Isoniazid with 2-Butynoic Acid. CrystEngComm, 2012, 14, 5124-5127.

(43) Aitipamula, S.; Wong, A. B. H.; Chow, P. S.; Tan, R. B. H. Novel Solid Forms of the AntiTuberculosis Drug, Isoniazid: Ternary and Polymorphic Cocrystals. CrystEngComm 2013, $15,5877-5887$.

(44) Mashhadi, S. M. A.; Yunus, U.; Bhatti, M. H.; Tahir, M. N. Isoniazid Cocrystals with AntiOxidant Hydroxy Benzoic Acids. J. Mol. Struct. 2014, 1076, 446-452.

(45) Ravikumar, N.; Gaddamanugu, G.; Anand Solomon, K. Structural, Spectroscopic (FT-IR, FT-Raman) and Theoretical Studies of the 1:1 Cocrystal of Isoniazid with P-Coumaric Acid. J. Mol. Struct. 2013, 1033, 273-279. 
(46) Sarcevica, I.; Orola, L.; Veidis, M. V; Belyakov, S. Cinnamic Acid Hydrogen Bonds to Isoniazid and N'-(propan-2-Ylidene)isonicotinohydrazide, an in Situ Reaction Product of Isoniazid and Acetone. Acta Crystallogr. Sect. C, Struct. Chem. 2014, 70, 392-395.

(47) Swapna, B.; Maddileti, D.; Nangia, A. Cocrystals of the Tuberculosis Drug Isoniazid: Polymorphism, Isostructurality, and Stability. Cryst. Growth Des. 2014.

(48) Lemmerer, A.; Bernstein, J.; Kahlenberg, V. Covalent Assistance in Supramolecular Synthesis: In Situ Modification and Masking of the Hydrogen Bonding Functionality of the Supramolecular Reagent Isoniazid in Co-Crystals. CrystEngComm, 2011, 13, 5692-5708.

(49) Lemmerer, A.; Bernstein, J.; Kahlenberg, V. One-Pot Covalent and Supramolecular Synthesis of Pharmaceutical Co-Crystals Using the API Isoniazid: A Potential Supramolecular Reagent. CrystEngComm 2010, 12, 2856-2864.

(50) Sevukarajan, M.; Sodanapalli, R.; Thanuja, B.; Nair, R. Preparation and Pharmaceutical Characterization of Supra Molecular Complex of Isoniazid with L ( + ) Tartaric Acid. $J$. Biomed. Sci. 2011, 3, 397-402.

(51) Grobely, P.; Mukherjee, A.; Desiraju, G. R. Drug-Drug Co-Crystals: Temperature-Dependent Proton Mobility in the Molecular Complex of Isoniazid with 4-Aminosalicylic Acid. CrystEngComm 2011, 13, 4358-4364.

(52) Lemmerer, A. Covalent Assistance to Supramolecular Synthesis: Modifying the Drug Functionality of the Antituberculosis API Isoniazid in Situ during Co-Crystallization with GRAS and API Compounds. CrystEngComm 2012, 14, 2465-2478.

(53) Sarcevica, I.; Orola, L.; Veidis, M. V; Podjava, A.; Belyakov, S. Crystal and Molecular Structure and Stability of Isoniazid Cocrystals with Selected Carboxylic Acids. Cryst. Growth Des. 2013, 13, 1082-1090.

(54) Greenspan, L. Humidity Fixed Points of Binary Saturated Aqueous Solutions. J. Res. Natl. Bur. Stand. 1977, 81, 89-96.

(55) Cheary, R. W.; Coelho, A. A Fundamental Parameters Approach to X-Ray Line-Profile Fitting. J. Appl. Crystallogr. 1992, 25, 109-121.

(56) Bhat, T. N.; Singh, T. P.; Vijayan, M. Isonicotinic Acid Hydrazide - a Reinvestigation. Acta Crystallogr. Sect. B Struct. Sci. 1974, 30, 2921-2922.

(57) Sim, G. A.; Robertson, J. M.; Goodwin, T. H. The Crystal and Molecular Structure of Benzoic Acid. Acta Crystallogr. 1955, 8, 157-164.

(58) Allen, F. H. The Cambridge Structural Database: A Quarter of a Million Crystal Structures and Rising. Acta Crystallogr. Sect. B Struct. Sci. 2002, 58, 380-388.

(59) Hartmann, S. R.; Hahn, E. L. Nuclear Double Resonance in the Rotating Frame. Phys. Rev. 1962, 128, 2042-2053.

(60) Wojdyr, M. Fityk : A General-Purpose Peak Fitting Program. J. Appl. Crystallogr. 2010, 43, 1126-1128. 
(61) Heiko, H.; Torsten, J. QI Offers next-Generation AFM Imaging Mode for Nanometrology. Laser Focus World 2012, 48, 25-30.

(62) Hutter, J. L.; Bechhoefer, J. Calibration of Atomic-Force Microscope Tips. Rev. Sci. Instrum. 1993, 64, 1868-1873.

(63) Monte, M. J. S.; Santos, L. M. N. B. F.; Fulem, M.; Fonseca, J. M. S.; Sousa, C. a. D. New Static Apparatus and Vapor Pressure of Reference Materials: Naphthalene, Benzoic Acid, Benzophenone, and Ferrocene. J. Chem. Eng. Data 2006, 51, 757-766.

(64) Cassidy, A. M. C.; Gardner, C. E.; Jones, W. Following the Surface Response of Caffeine Cocrystals to Controlled Humidity Storage by Atomic Force Microscopy. Int. J. Pharm. 2009, 379, 59-66.

(65) Boterashvili, M.; Lahav, M.; Shankar, S.; Facchetti, A.; van der Boom, M. E. On-Surface Solvent-Free Crystal-to-Co-Crystal Conversion by Non-Covalent Interactions. J. Am. Chem. Soc. 2014, 136, 11926-11929.

(66) Djikaev, Y.; Ruckenstein, E. Kinetic Model for the Sublimation of a Solid and Evaporation of Colloidal Particles from a Solid Substrate. J. Phys. Chem. 2008, 112, 1621-1627.

(67) Newman, A.; Zografi, G. Critical Considerations for the Qualitative and Quantitative Determination of Process-Induced Disorder in Crystalline Solids. J. Pharm. Sci. 2014, 103, $1-10$.

(68) Kolodziejski, W.; Klinowski, J. Kinetics of Cross-Polarization in Solid-State NMR: A Guide for Chemists. Chem. Rev. 2002, 102, 613-628. 


\section{Table of contents graphic}

Mechanistic and kinetic insight into spontaneous cocrystallisation of isoniazid and benzoic acid

Inese Sarceviča, Liāna Orola, Karol P. Nartowski, Yaroslav Z. Khimyak, Andrew N. Round and László Fábián

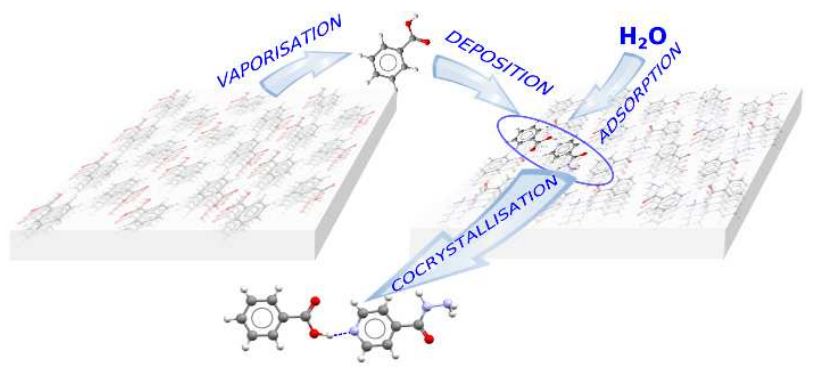

